\title{
NOTE
}

\section{Major sources of moisture for Antarctic ice-core sites identified through a Lagrangian approach}

\author{
Raquel Nieto, Ana María Durán-Quesada, Luis Gimeno* \\ Ephyslab (Environmental Physics Laboratory), Departamento de Física Aplicada, Facultad de Ciencias de Ourense, \\ Universidad de Vigo, Campus As Lagoas s/n, 32004 Ourense, Spain
}

\begin{abstract}
A Lagrangian method of diagnosis was used to identify the major sources of moisture for principal Antarctic ice-core sites by back-tracking the air masses that ultimately reach these regions for a 5 yr period (2000-2004). This method, making use of the FLEXPART model, allowed quantification of moisture sources with better horizontal and vertical resolution than has previously been achieved. FLEXPART computes every $6 \mathrm{~h}$ with a $1^{\circ} \times 1^{\circ}$ resolution and all 60 vertical levels of the European Centre for Medium-Range Weather Forecasts operational analysis. Our results confirm the previous identification of the sources of moisture in the Antarctic in relation to their subtropical origin, the region of major moisture contribution being centred on $40^{\circ} \mathrm{S}$ in a latitude band ranging between 30 and $50^{\circ} \mathrm{S}$.
\end{abstract}

KEY WORDS: Sources of moisture · Antarctic ice cores · Lagrangian approach · FLEXPART model

\section{INTRODUCTION}

Reconstruction of the historic Antarctic climate is generally based on isotope analysis (Lorius et al. 1979, Jouzel et al. 1996). At low tropospheric levels, relevant information on the water content of air masses can be obtained from ${ }^{2} \mathrm{H}$ and $\delta^{18} \mathrm{O}$ isotopes. Evaporation over the ocean surface can be analysed through the deuterium excess $\left(\delta^{2} \mathrm{H}-8 \delta^{18} \mathrm{O}\right)$; thus, information on moisture sources can be obtained from the interpretation of $\delta^{18} \mathrm{O}$ and deuterium profiles measured in ice cores. Isotopic depletion of vapour results from water vapour condensation during the formation of clouds (Araguas-Araguas et al. 2000), which allows the use of the Rayleigh distillation formulation (Dansgaard 1964) for moisture analysis. Precipitation, evaporation and sea ocean temperature are strongly linked to the deuterium excess and functional relationships between isotopes and climate parameters can, therefore, be established.

It is important to note that climate information recorded in ice cores is determined by the prevailing conditions during snowfall and the sources of moisture for ice-core extraction sites is a topic of evident interest. A variety of methods can be used to investigate moisture in the Antarctic region. Studies employing some of these are summarized in Table 1 along with their main results.

The use of a combination of deuterium excess as tracer and idealized isotope models by Petit et al. (1991) identified a subtropical origin of Antarctic moisture $\left(30^{\circ}\right.$ to $\left.40^{\circ} \mathrm{S}\right)$. Similar conclusions were drawn using atmospheric water balance studies (Peixoto \& Oort 1992), although the range of latitudes was larger $\left(8^{\circ}\right.$ to $\left.40^{\circ} \mathrm{S}\right)$. Studies based on $\delta^{18} \mathrm{O}$ (Bromwich \& Weaver 1983), general circulation models (Delmotte et al. 2000), or trajectories (Reijmer \& van den Broeke 2001, Reijmer et al. 2002) suggest a more southerly origin, ranging from $30^{\circ}$ to $60^{\circ} \mathrm{S}$ (Table 1 ).

In a 2-paper study, Stohl \& James $(2004,2005)$ applied a Lagrangian diagnostic method in order to determine the source of moisture in a basin. The study was based on meteorological analysis data, a particle 
Table 1. Antarctic moisture sources, applied analysis methods and main results

\begin{tabular}{|c|c|c|c|c|}
\hline Region & Method & Resolution & Results & Source \\
\hline $\begin{array}{l}\text { Law Dome (East Antarctica) } \\
\text { Dome A, Byrd, Vinson Massif, } \\
\text { Erebus, Estonian Transverse } \\
\text { to Dome B, Dumont d' Urville, } \\
\text { French pits in Adelie Land, } \\
\text { Amery Ice Shelf, Dronning } \\
\text { Maud Land (DML), Druzh- } \\
\text { naya, Potsdam Gletscher, } \\
\text { Ritscherflya }\end{array}$ & $\begin{array}{l}\text { Atmospheric } \\
\text { General Circula- } \\
\text { tion Model } \\
\text { (AGCM), which } \\
\text { includes water } \\
\text { isotopic cycles } \\
\text { and a simple } \\
\text { isotopic model }\end{array}$ & $40 \mathrm{~km}$ & $\begin{array}{l}\text { Subtropical origin of } \\
\text { Antarctic moisture }\end{array}$ & $\begin{array}{l}\text { Delmotte et al. (2000) } \\
\text { Masson-Delmotte et } \\
\text { al. (2008) }\end{array}$ \\
\hline DML & Trajectories & $\begin{array}{l}1.5 \text { in the horizontal plane, } \\
31 \text { levels in the vertical and } \\
6 \mathrm{~h} \text { in time } 5 \mathrm{~d} \text { trajectories }\end{array}$ & $\begin{array}{l}\text { Southerly origin of } \\
\text { Antarctic moisture }\left(30^{\circ} \text { to }\right. \\
\left.60^{\circ} \mathrm{S}\right)\end{array}$ & $\begin{array}{l}\text { Reijmer \& van den } \\
\text { Broeke (2001) }\end{array}$ \\
\hline $\begin{array}{l}\text { Byrd, DML05, Dome C, } \\
\text { Dome F, and Vostok }\end{array}$ & Trajectories & $\begin{array}{l}1.5 \text { in the horizontal plane, } \\
31 \text { levels in the vertical and } \\
6 \mathrm{~h} \text { in time } 5 \mathrm{~d} \text { trajectories }\end{array}$ & $\begin{array}{l}\text { The contributing latitude } \\
\text { band is } 50^{\circ} \text { to } 60^{\circ} \mathrm{S}\end{array}$ & Reijmer et al. (2002) \\
\hline Western DML & $\begin{array}{l}\text { Trajectories and } \\
\text { deuterium excess }\end{array}$ & $\begin{array}{l}1.0 \text { in the horizontal plane, } \\
60 \text { levels in the vertical and } \\
6 \mathrm{~h} \text { in time } 5 \mathrm{~d} \text { trajectories }\end{array}$ & $\begin{array}{l}\text { A moisture source area in } \\
\text { the southern Atlantic } \\
\text { Ocean for DML. Important } \\
\text { influence of the vertical } \\
\text { gradient in deuterium } \\
\text { excess over the moisture } \\
\text { source region }\end{array}$ & Helsen et al. (2006) \\
\hline
\end{tabular}

dispersion model, and a Lagrangian method analogue to the Eulerian budget method for diagnosing the surface moisture flux. The accuracy of this approach has allowed us to assess average values for moisture sources in the Mediterranean, Sahel and different locations in America (see e.g. Nieto et al. 2006, DuránQuesada et al. 2010 and references therein, for details). The main objective of the present study was to apply the Lagrangian method to identify the major sources of moisture for the main Antarctic ice-core sites by back-tracking air masses towards target regions.

\section{DATA AND METHODS}

As mentioned in the Introduction, this study is based on the method developed by Stohl \& James (2004, 2005), which uses the Lagrangian particle dispersion model FLEXPART (Stohl et al. 2005) and meteorological analysis data from the European Centre for Medium-Range Weather Forecasts (ECMWF 2002) to track atmospheric moisture along trajectories. In the FLEXPART model, wind fluctuations and convection are parameterised according to the Hanna (1982) and Emanuel \& Zivkovic-Rothman (1999) schemes, respectively. Particle transport and diffusion are described using the zero acceleration scheme. Details of the parameterisation schemes of the planetary boundary layer, mesoscale velocity fluctuations and particle splitting can be found in the FLEXPART technical note (Stohl et al. 2005). The basis of this method consists of dividing the atmosphere homogeneously into a large number of air parcels (particles), which are transported using the 3-dimensional wind field. The positions and specific humidity $(q)$ of the particles are recorded every $6 \mathrm{~h}$; this allows the calculation of increases $(e)$ and decreases $(p)$ in moisture along the trajectory through changes in $(q)$ with time $(t)$ related to the mass of the particle $(m)$ according to the following equation: $e-p=m \mathrm{~d} q / \mathrm{d} t$. Then, it is possible to obtain the surface freshwater flux $(E-P)$ by adding $(e-p)$ for the particles residing in the atmospheric column over an area; $(E)$ being the evaporation and $(P)$ the precipitation rate per unit area.

This study describes the tracking of 1398801 particles during a 5 yr period (2000-2004), computed using ECMWF operational analysis available every $6 \mathrm{~h}(00,06$, 12 and $18 \mathrm{~h} \mathrm{UTC}$ ) with a $1^{\circ} \times 1^{\circ}$ resolution and all 60 vertical levels of the analysis. The net freshwater flux $(E-P)$ was tracked backward from 3 ice-core sites: Byrd $\left(80^{\circ} \mathrm{S}\right.$, $\left.119^{\circ} \mathrm{W}\right)$, EPICA Dronning Maud Land (DML) $\left(75^{\circ} \mathrm{S}, 0^{\circ} \mathrm{E}\right)$ and Vostok $\left(78^{\circ} \mathrm{S}, 106^{\circ} \mathrm{E}\right)$. The target regions were defined by adding $4^{\circ}$ north and south latitude and $9^{\circ}$ east and west longitude to the location of the stations. The particles residing over the target regions were identified every $6 \mathrm{~h}$ and tracked backwards for $10 \mathrm{~d}$ (average residence time of water vapour in the atmosphere; Numaguti 1999). Through the integration of $(e-p)$ along subsequent time steps for the particles residing over the target regions, $(E-P)$ was estimated and averaged for seasonal, annual and 5 yr periods (individual daily values were estimated but only the $10 \mathrm{~d}$ integrated values are shown, given as $\left.(E-P)^{1-10}\right)$, to show the location of potential moisture sources for the target regions. 


\section{RESULTS}

Fig. 1 shows the positions of the ice-core stations and the 2000-2004 $(E-P)^{1-10}$ average for the target regions determined around the stations. In regions characterised by positive $(E-P)$ values, the excess of evapo- ration over precipitation indicates that air particles located within that column gain moisture; therefore, these regions are identified as potential moisture source regions. In contrast, negative $(E-P)$ values indicate that precipitation dominates over evaporation. As a consequence, air parcels located over those re-
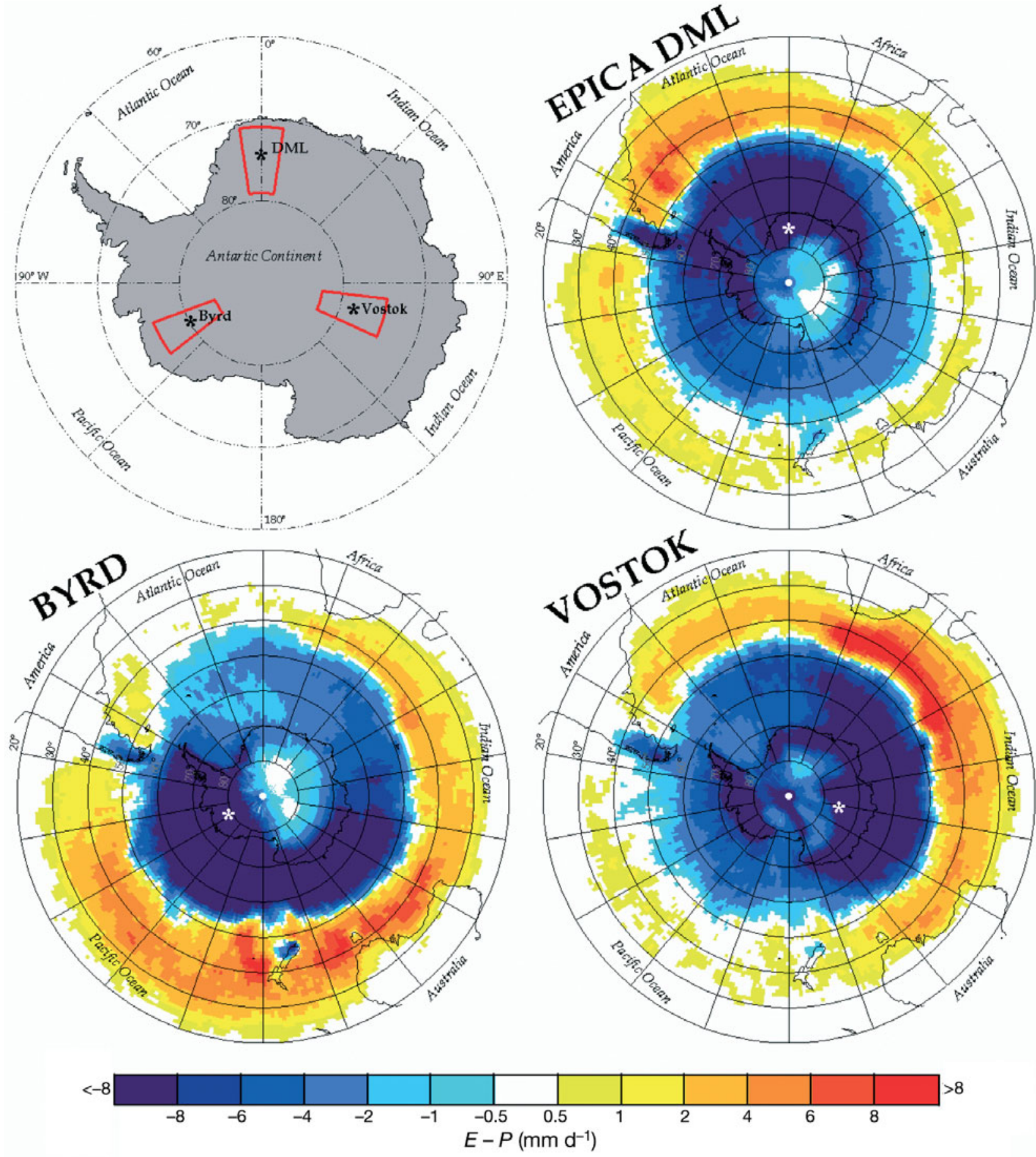

Fig. 1. The positions of the 3 studied Antarctic ice-core sites and the target regions defined around them (top left). For each target region, annual averages $\left(\mathrm{mm} \mathrm{d}^{-1}\right)$ of the aggregated $(E-P)$ values for the previous $10 \mathrm{~d}$ (period 2000-2004) for all the particles bound for the target region are shown 
gions (in transit to the target regions) present a net loss of moisture. Regions with negative values can, therefore, be considered moisture sink regions.

The map of $(E-P)^{1-10}$ shows the overall behaviour of particles over the previous $10 \mathrm{~d}$, including the average of all the gains and losses of moisture. From this aggregated perspective, 3 general results are obtained for the 3 target regions, namely:

(1) The latitude band between $30^{\circ}$ and $50^{\circ} \mathrm{S}$ is the main source of moisture for the Antarctic.

(2) The region of major contribution is centred on $40^{\circ} \mathrm{S}$ and displaced to the west of the region reflecting the cyclonic Antarctic circulation; for Byrd this is from $10^{\circ} \mathrm{W}$ (Western Pacific Ocean) to $100^{\circ} \mathrm{E}$ (Eastern Indian Ocean), for Vostok from $90^{\circ} \mathrm{E}$ (central Pacific Ocean) to $10^{\circ} \mathrm{E}$ (Eastern Atlantic Ocean) and for EPICA-DML from $20^{\circ}$ to $60^{\circ} \mathrm{W}$ (Central and Western Atlantic).

(3) The region to the south of $50^{\circ} \mathrm{S}$ is an area characterised by a net loss of moisture (a 'moisture sink'), this loss being highest between $60^{\circ}$ and $80^{\circ} \mathrm{S}$ over an area located around each station with an extension of $160^{\circ}$ longitude and elongated towards the west.

Temperature and isotope $\left({ }^{2} \mathrm{H}\right.$ and $\left.\delta^{18} \mathrm{O}\right)$ variations are related as a result of the 'continental effect' (MassonDelmotte et al. 2008). In the same way, variations in the moisture sources might be induced by temperature variations; this effect of continental temperature variations is a valid explanation for the maximum values observed near South America, Africa and New Zealand for EPICA-DML, Vostok and Byrd stations, respectively.

The seasonal patterns of the $(E-P)^{1-10}$ fields (not shown) present similar structures and positions to the observed annual pattern. However, the intensity of the moisture sources varies seasonally; Vostok presents the most variability, while Byrd maintains minor fluctuations in intensity. The sources seem to be more intense during austral autumn and winter, as found by Reijmer et al. (2002), as a result of longer distances travelled by the air masses during those periods. The observed variations reflect the expected seasonal temperature fluctuations, but variations in the wind components are the main factor responsible for the intensity variations throughout the year. These are related to the intensity of the local cyclonic circulations driven by variations in the pressure field.

\section{CONCLUDING REMARKS}

Using the Lagrangian approach described herein, we have been able to quantify the main sources of moisture in the Antarctic with a greater horizontal resolution than has previously been achieved. The results presented confirm the previous identification of the sources of moisture in the Antarctic in relation to their subtropical origin, but limit the source to $50^{\circ} \mathrm{S}$. This is not in total agreement with the results of other trajectory-based studies (see Table 1: Reijmer \& van den Broeke 2001, Reijmer et al. 2002) due to differences in the analysis methods. One reason for this disagreement is that our approach quantifies changes in the moisture along the trajectories, whereas previous Lagrangian approaches were based on estimating the percentage of ice-core station precipitation. The location of the stations in different latitude bands may also have influenced the results.

Acknowledgements. We thank Andreas Stohl for providing the trajectory data for the 2000-2004 period and 2 anonymous reviewers whose comments helped us to improve the manuscript.

\section{LITERATURE CITED}

Araguas-Araguas L, Froehlich K, Rozanski K (2000) Deuterium and oxygen-18 isotope composition of precipitation and atmospheric moisture. Hydrol Process 14:1341-1355

Bromwich DH, Weaver CJ (1983) Latitudinal displacement from main moisture source controls $\delta^{18} \mathrm{O}$ of snow in coastal Antarctica. Nature 301:145-147

Dansgaard W (1964) Stable isotopes in precipitation. Tellus 16:436-468

- Delmotte M, Masson V, Jouzel J, Morgan VI (2000) A seasonal deuterium excess signal at Law Dome, coastal eastern Antarctica: a southern ocean signature. J Geophys Res 105(D6):7187-7197

Durán-Quesada AM, Gimeno L, Amador JA, Nieto R (2010) Moisture sources for Central America. Identification of moisture sources using a Lagrangian analysis technique. J Geophys Res (in press). doi:10.1029/2009JD012455

ECMWF (2002) White PW (ed) IFS documentation. ECMWF, Reading

Emanuel KA, Živković-Rothman M (1999) Development and evaluation of a convection scheme for use in climate models. J Atmos Sci 56:1766-1782

Hanna SR (1982) Applications in air pollution modeling. In: Nieuwstadt FTM, van Dop H (eds), Atmospheric turbulence and air pollution modelling. D Reidel, Dordrecht

Helsen MM, van de Wal RSW, van den Broeke MR, MassonDelmotte V, Meijer HAJ, Scheele MP, Werner M (2006) Modeling the isotopic composition of Antarctic snow using backward trajectories: simulation of snow pit records. J Geophys Res 111:D15109. doi:10.1029/2005JD00 6524

Jouzel J, Waelbroeck C, Malaize B, Bender M, Petit JR and others (1996) Climatic interpretation of the recently extended Vostok ice records. Clim Dyn 12:513-521

Lorius C, Merlivat L, Jouzel J, Pourchet M (1979) A 30000 -yr isotope climatic record from Antarctic ice. Nature 280: $644-648$

Masson-Delmotte V, Hou S, Ekaykin A, Jouzel J and others (2008) A review of Antarctic surface snow isotopic composition: observations, atmospheric circulation, and isotopic modeling. J Clim 21:3359-3387

> Nieto R, Gimeno L, Trigo RM (2006) A Lagrangian identification of major sources of Sahel moisture. Geophys Res Lett 33:L18707. doi:10.1029/2006GL027232

Numaguti A (1999) Origin and recycling processes of precipi- 
tating water over the Eurasian continent: experiments using an atmospheric general circulation model. J Geophys Res 104:1957-1972

Peixoto JP, Oort AH (1992) Physics of climate. American Institute of Physics, New York

Petit JR, White JWC, Young NW, Jouzel J, Korotkevich YS (1991) Deuterium excess in recent Antarctic snow. J Geophys Res 96(D3):5113-5122

Reijmer CH, van den Broeke MR (2001) Moisture sources of precipitation in Western Dronning Maud Land, Antarctica. Antarct Sci 13:210-220

Reijmer CH, van den Broeke MR, Sceele MP (2002) Air parcel trajectories to five deep drilling locations on Antarctica,

Editorial responsibility: Peter Gleckler,

Livermore, California, USA based on the ERA-15 data set. J Clim 15:1957-1968

Stohl A, James P (2004) A Lagrangian analysis of the atmospheric branch of the global water cycle. I. Method description, validation, and demonstration for the August 2002 flooding in Central Europe. J Hydrometeorol 5: 656-678

Stohl A, James P (2005) A Lagrangian analysis of the atmospheric branch of the global water cycle. II. Moisture transports between Earth's ocean basins and river catchments. J Hydrometeorol 6:961-984

Stohl A, Forster C, Frank A, Seibert P, Wotawa G (2005) Technical note: the Lagrangian particle dispersion model FLEXPART version 6.2. Atmos Chem Phys 5:2461-2474

Submitted: June 16, 2009; Accepted: December 16, 2009

Proofs received from author(s): February 3, 2010 